\title{
Stakeholders' Perceived Satisfaction from the Use of CVCIRRD-Techno Gabay Technology Videos
}

\author{
JICA CESZARAINE O. PACATANG
}

ORCID NO. 0000-0002-0349-1031

jicaceszaraine@gmail.com

LEAH WILFREDA E. PILONGO

leahechavez@universityofbohol.edu.ph

ORCID Number: 0000-0001-6380-1831

JELINDA R. FORTICH

jrfortich@gmail.com

ORCID Number: 0000-0001-9328-3844

\begin{abstract}
Technology videos in this study served as medium to disseminate developmental information among farmers, fisher folks, small-scale entrepreneurs, and community members that were beneficiaries of Techno Gabay Program, a Philippine agricultural livelihood project. This study aimed to find out the utilization of technology videos and perceived satisfaction from the knowledge gained by the above-mentioned stakeholders. It made use of one-shot survey design and simple random sampling in respondent selection, frequency and percentage. Result showed that majority of the respondents voluntarily used the techno-videos that led them to be highly satisfied with the information given. The study implies the important effect of technology in imparting information.
\end{abstract}

\section{KEYWORDS}

Information Communication Technology, Techno Gabay, one-shot survey design, Bohol, Philippines. 


\section{INTRODUCTION}

In development-oriented programmes, there has always been the need to find the most effective and efficient means through which groups and great deal of people could be sensitized and motivated for change (Singhal and Rogers, 1999). The use of audio-visual aids had been shown to facilitate information transfer (Musa, 1984). And video, as one of the audio-visual materials, offers option for multiple uses in variety of communication situations. Opportunities for interactions and instant feedback add to its utility in education and development. Well-planned and executed projects in several developing nations bear testimony to the effectiveness of this new communication technology (Singh and Kumar, 1990). It was also found to be a powerful medium for use in development communication among rural poor by several researchers. The Worldview International Foundation (WIF) has observed that rural audience not only enjoyed video, but also understood the contents (Belbase, 1988). On the other hand, the Nutrition Center of the Philippines provides an excellent example of using video to increase the nutrition related knowledge of mothers (Anderson et al., 1987). Moreover, using video as a training tool has increased the flow of information from agricultural researchers, technicians, extension workers and other technical people, directly to farmers. Video enhances training by visualizing a verbal message with motion and color and standardize information (Alison et al, 1985).

Based on the above-cited experiences, TechnoGabay, a program that provides a framework for a more effective and sustainable strategy for bringing the needed information and technologies to the countryside, had explored on the use of technology videos to educate farmers and other stakeholders on farm production processes (ViCARP TechnoGabay Brochure 2006). The TechnoGabay program was conceived by the Philippine Council for Agriculture, Aquatic and Natural Resources Research and Development (PCAARRD) and implemented throughout the country through the various $R$ and $D$ consortia like the Central Visayas Consortium for Integrated Research and Development (CVCIRRD).

FITS or TechnoGabay Centers have computer units where these CDs or DVDs could be plugged in to get access to its content. In addition, the FITS Center has at least a telephone unit connected to IP servers for interested users to connect to the net or the worldwide web. More advanced TG Centers have improved their connectivity using the Wifi. The Center is also equipped with technology videos in digital (CD and/or DVD) format, VHS and CD/DVD players and a TV set, for interested users to view technology videos and/or video documentaries that 
would provide vicarious experiences for those who had no opportunity to go to other places to observe successful or outstanding farmers' farms.

People utilize mass media for satisfaction of their needs (Katz, Gurevitch and Haas, 1975). Needs is the gap between what is and what should be (Richardson et al. 2005). Richardson, who is an extension worker, classified needs as those expressed (what the targeted audience perceived as those they seek to have or to acquire, hence their needs) and observed (what the targeted audience sometimes thought they already have or possess but, as validated using a standard measure, they do not actually have or possess, hence still a need--sic). In developing our educational strategies, Richardson (2005) said, one should take into account both the observed and expressed needs.

Katz et al on the other hand, said that all media users have essentially the same five categories of needs. These are cognitive, affective, personal integrative, social integrative and tension release needs (Severin and Tankard, 2001).

Katz et al explained that cognitive needs are related to acquiring information, knowledge, and understanding of our environment. Affective needs are related to strengthening aesthetic, pleasurable and emotional experiences. The needs related to strengthening credibility, confidence, stability, and status of the individual are categorized as personal integrative needs. Needs related to strengthening contact with family, friends, and the world are called social integrative needs. Finally, tension release needs are those related to escape, tension release, and desire for diversion (Severin and Tankard, 2001).

Results of this study would help program implementers understand why people use and patronize a particular medium of communication like the technology video. It would also provide them with good insights to improve the TechnoGabay Center's services and strategies, to achieve the program's goal of bringing the technology to the farmer's doorstep so that they will improve their farm productivity and improve the quality of their life.

\section{OBJECTIVES}

Generally, the study aimed to find out if the Techno Gabay stakeholders find the use of the technology videos gratifying and whether the knowledge gained from the use of techno-videos had increased their productivity.

Specifically the study sought to:

1. Determine respondents' information needs, preferences, information seeking behavior (whether the exposure is voluntary or involuntary), and frequency of exposure to the video-referred to in this study as the 
communication variables;

2. Determine the factors that made the stakeholders decide to use the techno-videos as source of development information;

3. Find out stakeholders' perceived gratifications derived from the use of the techno-videos, perceived information needs satisfaction and its degree.

\section{THEORETICAL FRAMEWORK}

This study is mainly based on Uses and Gratification Theory. Blumler and Katz (1974) uses and gratification theory implies suggests that media users play an active role in choosing and using the media. Users take an active part in the communication process and are goal oriented in their media use. The theorist added that a media user seeks out a media source that best fulfills the needs of the user.

The theorists also stated that there are many grounds for utilizing the media, as there are media users. According to the theory, media consumers have the autonomy to choose the themes of the media they wanted to use and how it will affect them. Uses and gratification theory opens the idea that any forms of media can have an unconscious persuasion over our lives and how we see the world. The concept of using the media to satisfy ones needs does not fully be aware of the clout of the media in our community (Palmgreen et al 2001).

The individual's use of a certain medium is an indication that such medium satisfies his/her needs. It follows therefore that those who voluntarily watched the techno-videos at the Techno Gabay Center did so to satisfy their needs.

\section{REVIEW OF RELATED LITERATURE}

\section{Communication Media and Diffusion of Innovations}

Everett M. Rogers, a professor of rural sociology, popularized the diffusion theory in his 1962 book Diffusion of Innovations. He said diffusion is the process by which an innovation is communicated through certain channels over time among the members of a social system. Diffusion of Innovations is a theory that seeks to explain how, why, and at what rate new ideas and technology spread through cultures (Rogers et al, 1971). He also added that during communication, the idea is rarely evaluated from a scientific standpoint; rather, subjective perceptions of the innovation influence diffusion. The process occurs over time. Finally, social systems determine diffusion, norms on diffusion, roles of opinion 
leaders and change agents, types of innovation decisions, and innovation consequences.

Communication scholars believe that development that intends to bring about behavior change can only take place with an output of communication. Others claimed though that there are other factors in addition to communication, which are necessary for behavior change to occur (Singhal and Law, 1997).

Some social scientists though pointed out that information alone is not enough to bring about modifications in attitude and behavior, or to produce the kind of changes that development demands. Access to information by itself will not open any magic doors according to Bessette (1997). Bessette (1997) stressed that there must be opportunities for discussion and interchange, in order to deal with existing and new information, to relate different or contradictory viewpoints and opinions, to feed a communication process where people can become aware of what they are thinking and doing, weigh the various information and points of view exchanged, and make their own decisions.

To transfer knowledge and an awareness of the problems to small-scale farmers in the third world, it is necessary to use appropriate teaching and learning - in many cases, materials designed for illiterates. In some cases where literacy is well advanced, the rural population can be informed and instructed through appropriate materials such as leaflets, posters, comics and illustrated brochures. But because literacy among the rural population of most developing countries has not yet progressed this far, the formulation methods specially adapted for the transference of information to those who cannot read or write must be done (Scwab, et.al, 1995). Moreover, experts believe that the best strategy to reach out to less educated or illiterate audience is to use video where development messages could be disseminated easily through both voice and action. Audiovisual experts pointed out that learning is enhanced when one does not only hear what is being said but also see what is being talked about. The addition of motion makes video more effective as a communication medium.

Moreover, according to Jedlicka (1977), in order for information transfer to be successful in development cooperation, it is not enough to develop suitable criteria according to our own communication patterns. Such criteria must be based instead on the communication forms in rural societies of developing countries. In the field of visual communication, this means that we must study the existing experience with regard to how materials are perceived and understood in these societies. Finally, we should use this knowledge to produce appropriate extension media. This is where video becomes a potent tool. 


\section{Media Uses and Satisfaction}

In a 1973 study by Katz, Gurevitch and Haas, they saw the mass media as a means by which individuals connect or disconnect themselves with others. They developed 35 needs taken from the largely speculative literature on the social and psychological functions of the mass media and put them into five categories. These are cognitive, affective, personal integrative, social integrative, and tension release needs. An experimental study of whether an individual mood influences the choice of television program shows that subject makes intelligent decisions about selective exposure. Rubin and Bantz (1989) took a uses and gratifications approach to study another "new technology" by examining video cassette recorders (VCR) use. They found the following motives for VCR use: library storage of movies and shows, watching music videos, using exercise tapes, renting movies, letting children view, time-shifting, socializing by viewing with others, critical viewing including TV watching and studying tapes. Levy (1980) feels that people, who go to the trouble to use VCRs to time-shift programs, are the most active. The results of both projects show that people use VCRs for very specific purposes. Therefore, the Uses and Gratifications theory remind us that people use media for many purposes and as media users become increasingly confronted with choices, this approach should direct our attention to the audience or users of mass media.

This study tried to find out if the Techno Gabay clients of Maribojoc and Antequera in the province of Bohol who have been exposed to the technology videos placed at the FITS Centers have found their exposure or exposures to these techno-videos gratifying.

\section{Needs and Satisfaction}

Davison and Yu (1974) pointed out that students of uses and gratifications could try to work backwards, as it were, from gratifications to needs. In the informational field, for example, the surveillance function may be traced to a desire for security or the satisfaction of curiosity and the exploratory drive; seeking reinforcement of one's attitudes and values may derive from a need for reassurance that one is right; and attempts to correlate informational elements may stem from a more basic need (and other) media materials for "personal reference" may spring from a need of self-esteem; social utility functions may be traced to the need for affiliation; and escape functions may be related to the need to release tension and reduce anxiety. But whichever way one proceeds, they said that it is inescapable that what is at issue here is the long-standing problem of social and psychological science: how to (and whether to bother to) 
systematize the long list of human and societal needs. Thus far, gratifications research has stayed close to what we have been calling media-related needs (in the sense that the media have been observed to satisfy them, at least in part), but one wonders whether all this should not be put in the broader context of systematic studies of needs (Davison and Yu, 1974).

\section{METHODOLOGY}

This study employed a one-shot survey research design. Simple random sampling was used to select respondents. A list of stakeholders who have watched the FITS Center's technology videos shown was taken from the FITS Center's monitoring logbook with permission from the respective FITS Center Manager. From each FITS Center's list, 30 respondents were randomly selected or a total of 60 respondents from the two TechnoGabay Centers.

This study was conducted in the municipalities of Antequera and Maribojoc, Bohol. These places were chosen as study sites because these municipalities are CVCIRRD's implementing partners of the TechnoGabay program, hence it has well-established FITS Centers that make available technology videos for showing at the Center and for lending to interested stakeholders.

The researcher prepared videos to be utilized by the local government for information dissemination about different farming technologies. The video contained themes like farming, livestock production, aquaculture, vermiculture and backyard gardening, organic warming, waste management, livelihood entrepreneurial skills, resiliency to climate change. These were all explained in layperson's terms, in Sugboanong Binisaya.

\section{Data Analysis}

The data that were gathered in the study were encoded into a spreadsheet program and was run in the Statistical Package for Social Sciences (SPSS) Version 15 program for ease in analysis. Descriptive statistics such as frequency counts, totals, and percentile were used to describe both the communication and noncommunication variables. Results were presented in tabular, graphical and narrative forms. 


\section{RESULTS AND DISCUSSION}

Respondents' information needs

Table 1. Respondents' needs and need categories

$(\mathrm{N}=60)$

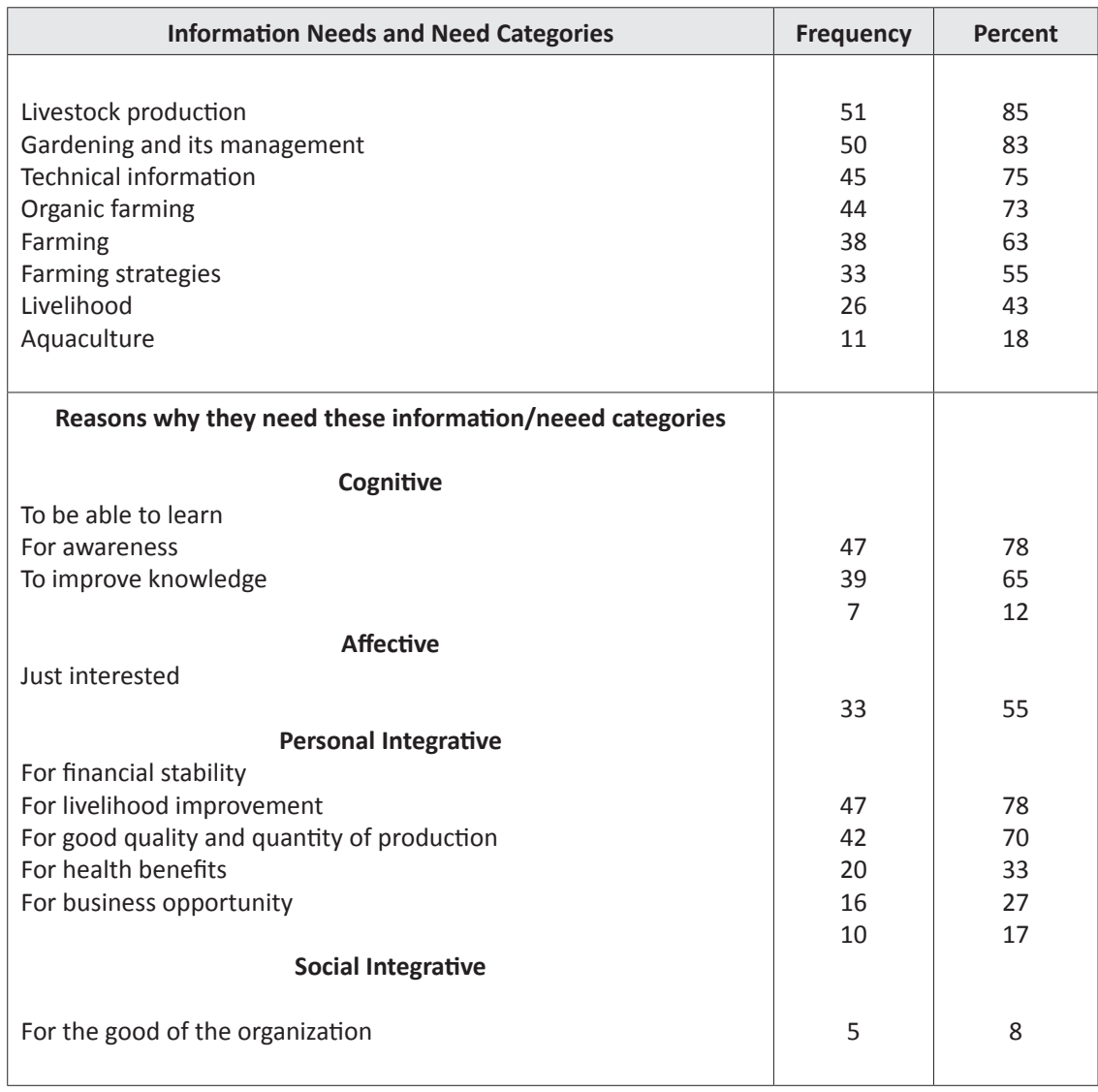

*Multiple Response

When asked what information they need, the respondents gave eight responses, and topping the list was the information on livestock production (85\%) closely followed by gardening and its management $(83 \%)$. Three-fourths (75\%) of them answered technical information on agriculture which was closely followed by organic farming (73\%). 
When asked why they need this information, respondents' answers were similar to those they enumerated when they were asked why they preferred that information. Their responses were categorized according to Katz, Gurevitch and Haas (1974) categories of needs-cognitive, affective, and personal integrative, social integrative and tension release. Not one of the responses can be categorized under tension release. To be able to learn, for awareness, and to improve knowledge could be categorized under cognitive need; just interested under affective need; for financial stability, for livelihood improvement, and for good quality, quantity of production, for health benefits and for business opportunity under personal integrative need.

Respondents' Reasons for their Information Preference

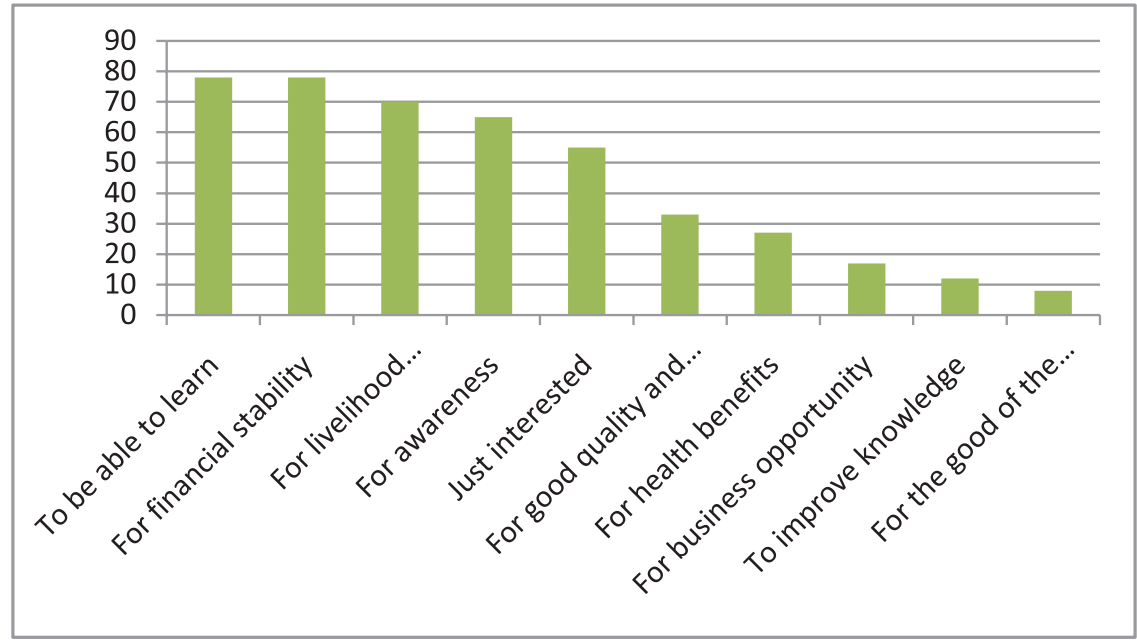

Figure 1. Respondents' reasons for their Information Preference $(\mathrm{N}=60)$

The respondents were asked why they would want to make the information to be made available in the FITS Center. The respondents gave 10 reasons. Foremost among the reasons were to be able to learn (78\%) and for financial stability (78\%).

This coincides with the statement of Bessette (1997) stressed that there must be opportunities for discussion and interchange, in order to deal with existing and new information, to relate different or contradictory viewpoints and opinions, to feed a communication process where people can become aware of what they are 
thinking and doing, weigh the various information and points of view exchanged, and make their own decisions.

Information seeking behavior and frequency of exposure

Table 2. Respondents' information seeking behaviour and frequency of exposure $(\mathrm{N}=60)$

\begin{tabular}{|c|c|c|}
\hline Variable/Response & Frequency & Percent \\
\hline \multicolumn{3}{|l|}{ Type of Exposure } \\
\hline - Voluntary exposure & 31 & 52 \\
\hline - Involuntary exposure & 29 & 48 \\
\hline \multicolumn{3}{|l|}{ Reasons for voluntary exposure: } \\
\hline To gain educational information (cognitive) & 56 & 93 \\
\hline Find it interesting to watch the techno-videos (affective) & 42 & 70 \\
\hline To increase income (personal integrative) & 40 & 67 \\
\hline For improvement of business (personal integrative) & 20 & 33 \\
\hline \multicolumn{3}{|l|}{ Reasons for involuntary exposure: } \\
\hline For socialization (social integrative) & 29 & 48 \\
\hline We were encouraged by the TG technicians (social integrative) & 29 & 48 \\
\hline We were required to watch the techno-videos (social integrative) & 24 & 40 \\
\hline
\end{tabular}

${ }^{*}$ Multiple Response

Information-seeking behavior refers to the respondent's behavior towards the media that makes them expose their selves either voluntarily or involuntarily to the techno-videos especially the ones that carry the information that they need. Results showed that slightly more than one half (52\%) of the respondents were voluntarily exposed to the techno-videos and the rest of them $(48 \%)$ were exposed involuntarily.

Voluntary and involuntary exposures of the respondents were determined based on their responses. For voluntary exposures, majority (93\%) of them said that the reason why they watched the techno-videos was to gain educational information. Less than three-fourths $(70 \%)$ of the respondents answered that they find it interesting to watch the techno-videos, and slightly over two-thirds of them answered to increase their source of income.

Topping the reasons for the respondents' involuntary exposures to the techno-videos was for socialization (48\%) and they were encouraged by the TG technicians (48\%). Two-fifths (40\%) said they were required to watch the technovideos by the technicians. 
According to Laney (1997) the community can use the video to convince other intermediaries to understand their problems, and enable them to identify what assistance they might need from other service providers.

\section{Frequency of Exposure}

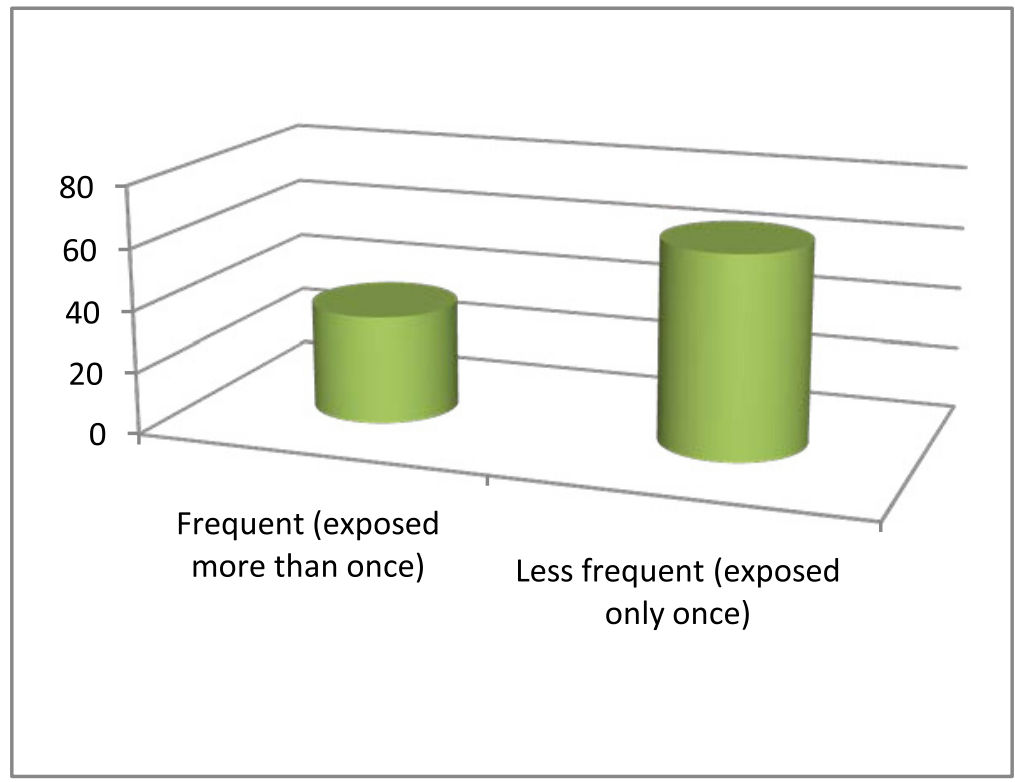

Figure 2. Respondents' frequency of exposure

$(\mathrm{N}=60)$

Frequency of exposure is the number of times that the respondents were able to watch the technology videos. Frequency was categorized into two: frequent and less frequent. Frequent means they have watched it more than once and less frequent means they have watched it only once.

Results showed that only a little more than one-third (35\%) have frequently watched the techno-videos. On the other hand, almost two-thirds (65\%) of the respondents have watched their preferred videos only once or less frequently. 


\section{Perceived Satisfaction}

Table 3. Respondents' perceived gratifications from their exposure to the techno-videos

\begin{tabular}{|l|c|c|}
\hline \multicolumn{1}{|c|}{ Perceived Satisfaction } & Frequency & Percent \\
\hline \multicolumn{1}{|c|}{ No } & & \\
\hline Did you get anything from watching techno-videos? & 55 & 92 \\
& & 8 \\
\hline & & \\
Perceived Satisfaction (n=55) & & \\
Gained knowledge about farming & 45 & 81 \\
Learned procedures, advantages, importance and effects of organic & 43 & 78 \\
farming & & \\
Learned how to adapt to the different farming technology & 43 & 78 \\
Increase in productivity has supported the educational financial needs of & 39 & 71 \\
children & & \\
Gained confidence & 37 & 67 \\
Gained information on agriculture & 28 & 51 \\
Learned techniques on effective fishing & 13 & 24 \\
Sustained the production and status of the business & 13 & 24 \\
Earned job promotions & 5 & 9 \\
Helped preserved the environment & 4 & 7 \\
& & \\
\hline
\end{tabular}

*Multiple Response

When asked if they got anything from their exposures to the techno-videos, the majority (92\%) said yes, while only few $(8 \%)$ said no. They were asked what they got out of using the techno-videos as source of information. Topping the list of responses was had gained knowledge about farming (81\%). Other respondents (78\%) said they have learned the procedures, advantages, importance, and effects of organic farming. An equal number of respondents (78\%) said they learned how to adapt to the new farming technology.

This confirms the findings saying that gratifications research has stayed close to what we have been calling media-related needs, but one wonders whether all this should not be put in the broader context of systematic studies of needs (Davison and Yu, 1974) 
Respondents' Needs that were gratified

Table 4. Respondents' needs that were gratified

$(\mathrm{N}=60)$

\begin{tabular}{|l|c|c|}
\hline \multicolumn{1}{|c|}{ Needs gratified } & Frequency & Percent \\
\hline the need to learn the innovation (cognitive) & 49 & 82 \\
\hline the need for additional knowledge (cognitive) & 49 & 82 \\
\hline the need for financial stability (personal integrative) & 47 & 78 \\
\hline the need to gain confidence (affective) & 42 & 70 \\
\hline the need for cheaper costing of farming expenses (personal integrative) & 22 & 37 \\
\hline the need to meet the goal of organization (social integrative) & & 23 \\
\hline
\end{tabular}

*Multiple Response

The needs that were gratified through the use of techno-videos were determined in this study. Results showed that majority of the respondents (82\%) found the need to learn the innovation and when it comes to farming management, the need to improve their farm production, and the need for additional knowledge have been greatly gratified (82\%). This was closely followed by the need for financial stability (78\%).

A study also conducted to draw on the uses and gratification perspective in mass communication research to examine the audience experience associated with social-media. The results reported show similar to the concept of the theory itself reported in studies of other media. New perspective called personal involvement and continuing relationship were discovered and established to be essential factors (LaRose et al 2004).

\section{Respondents' Degree of Need Satisfaction}

Table 5. Respondents' degree of need satisfaction

\begin{tabular}{|c|c|c|}
\hline Category & Frequency & Percent \\
\hline $\begin{array}{c}(\mathrm{n}=51) \\
\text { Slightly satisfied }\end{array}$ & 10 & 17.0 \\
\hline Moderately satisfied & 25 & 41.5 \\
\hline Highly satisfied & 25 & 41.5 \\
\hline
\end{tabular}


Respondents were also asked how satisfied they are with the information they have obtained from their exposure from the techno-videos. The responses were categorized as: slightly satisfied, moderately satisfied and highly satisfied. The answers were measured through the use of scale with an option that follows: 1-slightly satisfied, 2-moderately satisfied, 3-highly satisfied. Results showed that there was an equal number of respondents who were moderately $(41.5 \%)$ and highly (41.5\%) satisfied. Only one-sixth (17\%) were slightly satisfied.

\section{Respondents' Perceived Information Needs Satisfaction}

Table 5. Respondents' perceived needs satisfaction, needs satisfied and why $(\mathrm{N}=60)$

\begin{tabular}{|c|c|c|}
\hline Needs satisfaction & Frequency & Percent \\
\hline Did the techno-videos satisfy your needs? & & \\
\hline Yes & 51 & 85 \\
\hline No & 9 & 15 \\
\hline Needs Satisfied $(n=51)$ & & \\
\hline The needs to sustain the basic needs of the family & 47 & 92 \\
\hline The need to gain high quality and quantity of production & 45 & 88 \\
\hline Financial needs to support the educational needs of their children & 43 & 84 \\
\hline The need to have a healthy lifestyle & 29 & 57 \\
\hline The need to generate income for the organization & 19 & 37 \\
\hline The need to earn job and promotions & 5 & 10 \\
\hline Why the needs were satisfied? $(n=51)$ & & \\
\hline Able to sustain the needs of the family due to the increase of income & 49 & 96 \\
\hline Respondents' children are now professional & 44 & 86 \\
\hline Protects the family from calamities and provides the comfort of living & 37 & 72 \\
\hline Healthy living & 34 & 67 \\
\hline Full participation and cooperation from the organization & 21 & 41 \\
\hline
\end{tabular}

\section{*Multiple Response}

The respondents were asked if their information needs were satisfied through the use of the techno-videos. More than four-fifths (85\%) of the respondents said yes, while only a few of them (15\%) said no.

Majority of the respondents (92\%) claimed that the need to be able to sustain the basic needs of their family was satisfied. Followed by the need to gain high quality and quantity of production (88\%). On the other hand, over four-fifths 
(84\%) claimed that the need to have a healthy lifestyle was satisfied as well. The rest of the responses are shown in Table 17 below.

The respondents were also asked why the needs were satisfied by the information they got out of the techno-videos. Majority of the respondents (96\%) claimed that they are able to sustain the basic needs of the family. Moreover, more than four-fifths (86\%) claimed that their children are now professionals because they were able to send their children to college.

\section{CONCLUSION}

1. Media use has a gratifying effect. The majority of the respondents exposed their selves voluntarily to the technology videos to satisfy their information needs. However, even those who were involuntarily exposed to the technology videos and who said that, they just happened to be attending the seminars organized by the DA staff and the technology videos were played while they were waiting for other farmers to arrive, have claimed that their exposure/s to the various technology videos have satisfying effects on them-foremost of which was the satisfaction of their cognitive needs such as the videos creating awareness of farming information and the technology videos inculcating knowledge about farming techniques. In fact, an equal number of respondents claimed of the satisfaction of their personal integrative needs like increase in income, livelihood improvement and financial stability. Some respondents also mentioned the satisfaction of their affective need claiming that the technology videos were interesting and have entertained them and that the videos helped them gain self-confidence. A few claimed that the videos had satisfied their social integrative needs.

2. Information seeking behavior seems to step up as the need to satisfy cognitive needs increases. The respondents, who are mostly farmers, voluntarily sought for the farming-related information and have repeatedly exposed their selves to the technology videos because they needed the information to increase their farm productivity, a personal integrative need. This finding once again supported what has been postulated in the Reinforcement Theory by Bandura (1994). This theory postulated that when a particular action is rewarded or being reinforced, there is a tendency for the person to repeat that rewarded action. In this case, the respondents' needs -cognitive, affective, personal integrative and social integrative-were satisfied, hence the respondents, especially the farmer-respondents, had repeatedly exposed themselves to the technology 
videos provided by the TechnoGabay Centers of Antequera and Maribojoc, Bohol. This seems to corroborate with Katz, Gurevitch and Haas' (1975) Uses and Gratification Theory.

3. With the many gratifying effects from exposure to the technology videos and the very high needs satisfaction as shown in the respondents' moderate $(41.5 \%)$ and high $(41.5 \%)$ degree of satisfaction, there is no doubt that video is a vital instrument in educating the farmers and in attitude formation and in behavior change. And, since many of the respondents have claimed of high need satisfaction even if their exposure to the technology videos were involuntary-that is, because the videos were played before the start of trainings, seminars and meetings--these information dissemination strategies, that is, group media plus techno-videos, should be employed by development workers/facilitators. In other words, they should make it a habit to play technology videos before the start of a meeting, training, seminar-workshop, symposium and forum or even as an intermission.

\section{LITERATURE CITED}

Allison, P., \& Benjamin, P. R. (1986). Short Communications: Stimulation of Neuritic Outgrowth in an Undamaged Molluscan Interneurone. Journal of experimental biology, 122(1), 447-451. Retrieved from http://goo.gl/ kGQAS5. (Accessed last June 4, 2013)

Anderson, R. M., May, R. M., \& Mclean, A. R. (1988). Possible demographic consequences of AIDS in developing countries. Retrieved from http:// goo.gl/VernMi. (Accessed last July 10, 2013).

Belbase, K., \& Morgan, R. (1994). Food security and nutrition monitoring for drought relief management: The case of Botswana. Food Policy, 19(3), 285-300.

Bessette, J. M. (1997). The mild voice of reason: Deliberative democracy and American national government. University of Chicago Press. Retrieved from http://goo.gl/iCTLI8. (Accessed last July 5, 2013)

Blumler, J. G. (1979). The role of theory in uses and gratifications studies. Communication research, 6(1), 9-36. Retrieved from http://goo.gl/ 
sFLrW3. (Accessed last July 3, 2013)

Blumler J.G. \& Katz, E. (1974). The uses of masscommunications: Current perspective on gratification research. Beverly Hills, CA: Sage. Retrieved from http://goo.gl/T7qJ5. (Accessed last July 6, 2013)

Harper, J. (1991). The forms and orders of western liturgy from the tenth to the eighteenth century: A historical introduction and guide for students and musicians. Oxford University Press.

Jedlicka, A. D. (1977). Organization for rural development. Risk taking and appropriate technology. Praeger Special Studies in International Economics and Development (USA). Retrieved from http://goo.gl/ w7aHwx. (Accessed last July9, 2013)

Laney, S. T. (1997). U.S. Patent No. 5,668,932. Washington, DC: U.S. Patent and Trademark Office. Retrieved from http://goo.gl/HXGgw4. ( Accessed last July7, 2013)

LaRose, R., \& Eastin, M. S. (2004). A social cognitive theory of Internet uses and gratifications: Toward a new model of media attendance. Journal of Broadcasting \& Electronic Media, 48(3), 358-377. Retrieved from http:// goo.gl/15oOii. (Accessed last July 10, 2013)

Katz, E., Blumler, J. G., \& Gurevitch, M. (1973). Uses and gratifications research. Public opinion quarterly, 509-523. Retrieved from http://goo. gl/eexqJ6. (Accessed last June 4, 2013)

Palmgreen, P., Wenner, L. A., \& Rosengren, K. E. (1985). \{Uses and Gratifications Research: The Past Ten Years\}. Retrieved from http://goo.gl/bKj5KS. (Accessed last July 13, 2013)

Musa, S., Ziatdinov, R., \& Griffiths, C. (2013). Introduction to computer animation and its possible educational applications. arXiv preprint arXiv:1312.1824. Retrieved from http://goo.gl/i6Ec3T. (Accessed last June 13, 2013). 
Richardson, A. D., Hollinger, D. Y., Burba, G. G., Davis, K. J., Flanagan, L. B., Katul, G. G., ... \& Wofsy, S. C. (2006). A multi-site analysis of random error in tower-based measurements of carbon and energy fluxes. Agricultural and Forest Meteorology, 136(1), 1-18. Retrieved from http://goo.gl/ D9SwuC. (Accessed last July 18, 2013)

Rogers, E. M., \& Shoemaker, F. F. (1971). Communication of Innovations; A Cross-Cultural Approach. Retrieved from http://goo.gl/3zpvO0. (Accessed last July 7, 2013)

Ruggiero, T. E. (2000). Uses and gratifications theory in the 21st century. Mass communication \& society, 3(1), 3-37.retrieved from http://goo. gl/70QyaC. (Accessed last July9, 2013).

Schwab-Stone, M., Chen, C., Greenberger, E., Silver, D., Lichtman, J., \& Voyce, C. (1999). No safe haven II: The effects of violence exposure on urban youth. Journal of the American Academy of Child \& Adolescent Psychiatry,38(4), 359-367. Retrieved from http://goo.gl/iF5Djm. Accessed last June 6, 2013).

Severin, W. J., \& Tankard Jr, J. W. (2001). Communcation Theories. University of Texas at Austin.

Singhal, A., \& Rogers, E. M. (1999). Entertainment-education: A communication strategy for social change. Routledge. Retrieved from http://goo. gl/6y7LLt. ( Accessed last June 15, 2013)

Singhal, A., \& Law, S. (1997). A Research Agenda for Diffusion of Innovations Scholars in the 21st Century: A Conversation with Everett M Rogers. J. Develop. Comm., 8, 39-39. Retrieved from http://goo.gl/z8ggsP. (Accessed last June 24, 2013).

ViCARP TechnoGabay Brochure 2006 